\title{
SYNTHESIS AND STUDY OF BIMETALLIC CATALYTIC SYSTEMS FORMED IN SITU BY ALUMINUM, 1, 2-DICHLOROETHANE AND Fe (III), $\mathrm{Ni}$ (II), Mn (II) CHLORIDES
}

H.J.Ibragimov ${ }^{a}$, K.M.Gasimova ${ }^{a^{\star}}$, Z.M.Ibragimova ${ }^{a}$, I.V.Kolchikova ${ }^{a}$, Mai M. Khalaf ${ }^{a, b}$, A.E.Alieva ${ }^{a, c}$ ${ }^{a}$ Institute of Petrochemical Processes, Azerbaijan National Academy of Sciences, Khojaly Ave. 30, AZ1025

Baku, Azerbaijan

E-mail address: kenul.qasimova@gmail.com

${ }^{b}$ Chemistry Department, Faculty of Science, Sohag University, 82524 Sohag, Egypt

E-mail address: mai kha1@yahoo.com

${ }^{c}$ Azerbaijan State Oil Academy, AZ1010 Baku, Azerbaijan

ABSTRACT

E-mail address: aynura82@yahoo.com

Novel bimetallic catalytic systems based on the catalytic complex (CTC) are synthesized from the reaction of Al metal and 1, 2-dichloroethane in the mode of in situ and modified with the metal chlorides of Mn (II), Fe (III), and Ni (II) in paraffin medium. The structures of synthesized catalytic samples were confirmed by bulk and surface characterization with FTIR, X-ray diffraction (XRD), thermal analyses (TG/DTG/DTA), dynamic light scattering spectroscopy (DLS) for determination the particle size and X-ray fluorescence microscopy (XRFM).

\section{Keywords}

CTC, CTC/FeCl 3 , CTC/NiCl $2, \mathrm{CTC} / \mathrm{MnCl}_{2}, \mathrm{XRFM}, \mathrm{TG} / \mathrm{DTG} / \mathrm{DTA}, \mathrm{XRD}$.

\section{Academic Discipline And Sub-Disciplines}

Catalysis

\section{SUBJECT CLASSIFICATION}

Chemistry

\section{TYPE (METHOD/APPROACH)}

Experimental study

\section{Council for Innovative Research}

Peer Review Research Publishing System

Journal: Journal of Advances in Chemistry

Vol 3, No. 1

editor@cirworld.com

www.cirworld.com, member.cirworld.com 


\section{INTRODUCTION}

As it is known [1, 2], the production of low molecular weight petrochemical complex olefins, particularly ethylene and propylene is carried out by the pyrolysis of raw hydrocarbons. Moreover, along with the desired products the liquid pyrolysis products which are formed in its composition with significant amounts are very valuable for organic synthesis of unsaturated and aromatic hydrocarbons depending on the feedstock nature and the process conditions. Consequently, the liquid products of pyrolysis (LPP) can be represented as an effective source of raw material for producing aromatic hydrocarbons (benzene, toluene, xylenes) and various petroleum resins resulting from the oligomerization process of unsaturated compounds in its composition. This makes the treatment of LPP to produce the above products are very up to date $[3,4] . \mathrm{AlCl}_{3}$ is the most famous catalyst used for the synthesis of PPRs or its complexes with various compounds, including catalysts of the Ziegler-Natta type based on alkylaluminum. However, these catalysts do not have sufficient activity and stability and therefore are used in large quantities for carrying out the process [5-8]. To overcome all these drawbacks, catalytic complex (CTC) of the cationic type based on the reaction of aluminum metal and 1,2-dichloroethane was synthesized, and this type of catalytic complex showing a higher activity in comparison with other aluminumcontaining catalysts in the processes of stable oligomerization and alkylation processes in the presence of LPP complex processing which is carried out with obtaining high purity of benzene fraction and PPRs.

Application of a new catalytic complex (CTC) for the LPP processing, along with obtaining high purity aromatics and PPRs as by product and used as coatings in the paint industry and road bitumen additives, provides a significant cost reduction of the overall process $[9,10]$. However, despite the fact that the synthesized catalytic complex based on aluminum dichloroethane as compared to other catalysts exhibit cationic activity greater stability in the test process involving its low molecular weight forms (PPR). To further enhancement of the catalytic behavior and high purity of PPRs there is a need for modification of these catalysts. For this purpose, the catalytic complex of Al-dichlorethane was modified with the transition metal chlorides. This is not only to improve the characteristic quality of the oligomerization products which is very important from the practical side, but at the same time to improve the efficiency of the pirocondensate recycling process [11].

This paper presents the results of the synthesis and the structure study of the catalytic systems CTC and its modified forms of $\mathrm{Mn}$ (II), Fe (III), and Ni (II) metal chlorides.

\section{EXPERIMENTAL}

\subsection{Synthesis of the bimetallic catalysts}

The synthesis routs of bimetallic catalysts were carried out in laboratory conditions in the mode of in situ in a threenecked flask equipped with mechanical stirrer, reflux condenser and thermometer. The influence of temperature, effect of reaction time, the effect of solvent nature, and the ratio of components including the molar ratio of Al:Me were studied for the process. The formed bi-metal complexes are designated as CTC/NiCl $2, \mathrm{CTC} / \mathrm{MnCl}_{2}$, and CTC/FeCl 3 . These bimetallic complexes were further calcined at $800^{\circ} \mathrm{C}$ in air to be analyzed by XRD method.

\subsection{Characterization techniques}

\subsubsection{Dynamic light scattering Particle Size (DLS)}

Particle size and size distribution of the catalytic systems were determined by dynamic light scattering (DLS) with particle size analyzer LB550, Horiba in 1, 2-dichloroethane as solvent at $25^{\circ} \mathrm{C}$.

\subsubsection{Thermal analysis (TG/DTG/DTA)}

Thermal analysis (TG/DTG/DTA) was performed on thermograph Q-1500D MOM in the temperature range 20$800^{\circ} \mathrm{C}$ in flowing of air. The rate of heating oven was $10^{\circ} \mathrm{C} / \mathrm{min}$, with using calcined alumina as reference sample.

\subsubsection{X-ray diffraction (XRD)}

XRD patterns of the samples were recorded on an automatic diffractometer "D2 PHASER" Company Bruker (Germany) at room temperature. Diffraction patterns were obtained with Ni-filtered CuKa radiation $(\lambda=0.15418 \mathrm{~nm})$, monochromatic X-ray beam, and X-ray tube parameters with $35 \mathrm{kv}$ and $25 \mu \mathrm{A}$.

\subsubsection{FTIR spectra}

IR spectra of the samples were recorded on a spectrophotometer "Bruker ALPHA FT-iR" in the range of 400-4000 $\mathrm{cm}^{-1}$ at $25^{\circ} \mathrm{C}$. The spectra have been explained based on the literature [12-16].

\subsubsection{X-ray fluorescence microscopy (XRF)}

X-ray fluorescence microscopy XGT-7000 Horiba (XRF) was used to determine the elemental composition and the distribution of elements in layers of the catalytic systems. Accelerating voltage of $15 \mathrm{kV}$ was used in determining the $\mathrm{Al}$ and $\mathrm{Cl}$-elements, and for the elements $\mathrm{Mn}, \mathrm{Fe}$, Ni were determined by using X-ray tube voltage of $50 \mathrm{kV}$ with a diameter of the incident X-ray beam 100 microns, the measurement time was $200 \mathrm{sec}$. for each sample. Before measurements, the samples were crushed to powder and pressed at pressure $20 \mathrm{tor} / \mathrm{cm}^{2}$. 


\section{RESULTS AND DISCUSSION}

During the synthesis process of the catalyst, it was primarily studied the role of the solvent used in this process. Practically, it has been shown that by using benzene and its monosubstituted derivatives as solvent aromatic hydrocarbons are formed during the initial reaction period of aluminum chloride exerting a catalytic effect on the interaction of aromatic hydrocarbons with dichloroethane (DCE) contributes to their accumulation in the polycondensation system of polyphenylethyl and making it impossible to synthesis the catalytic systems. Using of normal hydrocarbon as solvent makes the synthesis conditions of the catalyst with a high yield is easy. By the chromatographic analysis of the gases separated in the synthesis process of the catalytic complex, it was suggested that the solvent molecules in the process act as a hydrogen donor, and further transformed into low molecular weight branched chain of hydrocarbons and after that are removed from the system. The compositions of the gases generated in the process are listed in Table 1.

Table 1. The results of the chromatographic analysis of the gases generated in the synthesis process of bimetallic catalytic systems $\mathrm{CTC}$ and $\mathrm{CTC} / \mathrm{NiCl}_{2}$

\begin{tabular}{|l|c|c|}
\hline \multirow{2}{*}{ Hydrocarbons } & \multicolumn{2}{|c|}{ \% wt. } \\
\cline { 2 - 3 } & CTC & CTC/NiCl 2 \\
\hline Ethane, Ethylene & 8.35 & 10.13 \\
\hline Propane, Propylene & 15.33 & 14.82 \\
\hline Iso-butane & 14.38 & 9.7 \\
\hline butylene & 17.39 & 4.22 \\
\hline n-butane & 7.5 & 2.28 \\
\hline Divinyl & 4.82 & 17.42 \\
\hline iso-Pentane & 8.3 & 2.99 \\
\hline n- Pentane & 8.28 & 2.96 \\
\hline 2.2-dimethylpropane & 0.9 & 3.55 \\
\hline 2.2- dimethylbutane & 1.64 & 5.06 \\
\hline 2.3- dimethylbutane & 3.2 & 4.19 \\
\hline 2- methylpentane & 2.13 & 3.96 \\
\hline 3- methylpentane & 0.83 & 6.28 \\
\hline n-hexane & 3.9 & 8.48 \\
\hline 2.4- methylpentane & 3.05 & \\
\hline & & \\
\hline
\end{tabular}

It is found that, the hydrocarbon composition of the gases generated in the synthesis process of the CTC and the bimetallic catalytic systems is identical, and the numbers of them are different. In bimetallic systems with transition metals unlike CTC observed a higher content of branched chain hydrocarbons and lower content of the hydrocarbon of ethane, ethylene and propane-propylene. This can explain the complex formation of bimetallic catalytic system by modifying the sample of CTC. The mechanism of formation of bimetallic complex can be represented as follows (Scheme 1):

The presence of carbon particles in the system can be explained by the reduction of methyl and ethyl radicals which formed during the reaction and by the presence of free carbon on the activated aluminum surface.

In the systems $\mathrm{Al}+\mathrm{DCE}+$ heptane $+\mathrm{Me}_{\mathrm{x}} \mathrm{Cl}_{\mathrm{y}}$ full interaction of the components is directly related to the nature of the solvent and the molar ratio of the used components, temperature and reaction time. 


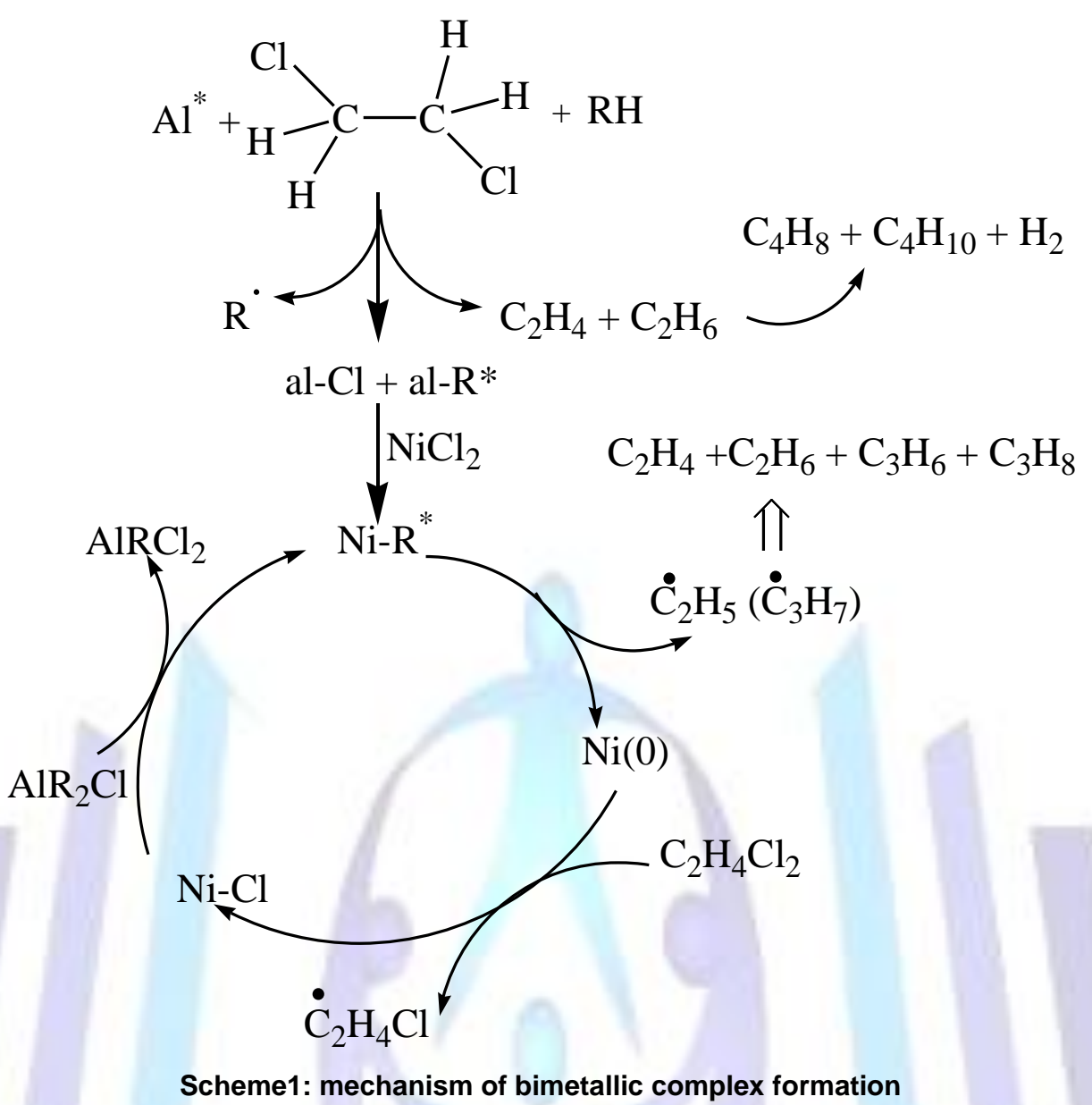

$\mathrm{Al}^{*}$ - Activated aluminum; al - 1/3Al; $\mathrm{R}^{*} \cdot \cdot \mathrm{C}_{2} \mathrm{H}_{5}, \cdot \mathrm{C}_{3} \mathrm{H}_{7}$ radicals, $\mathrm{RH}$ - solvent (heptane)

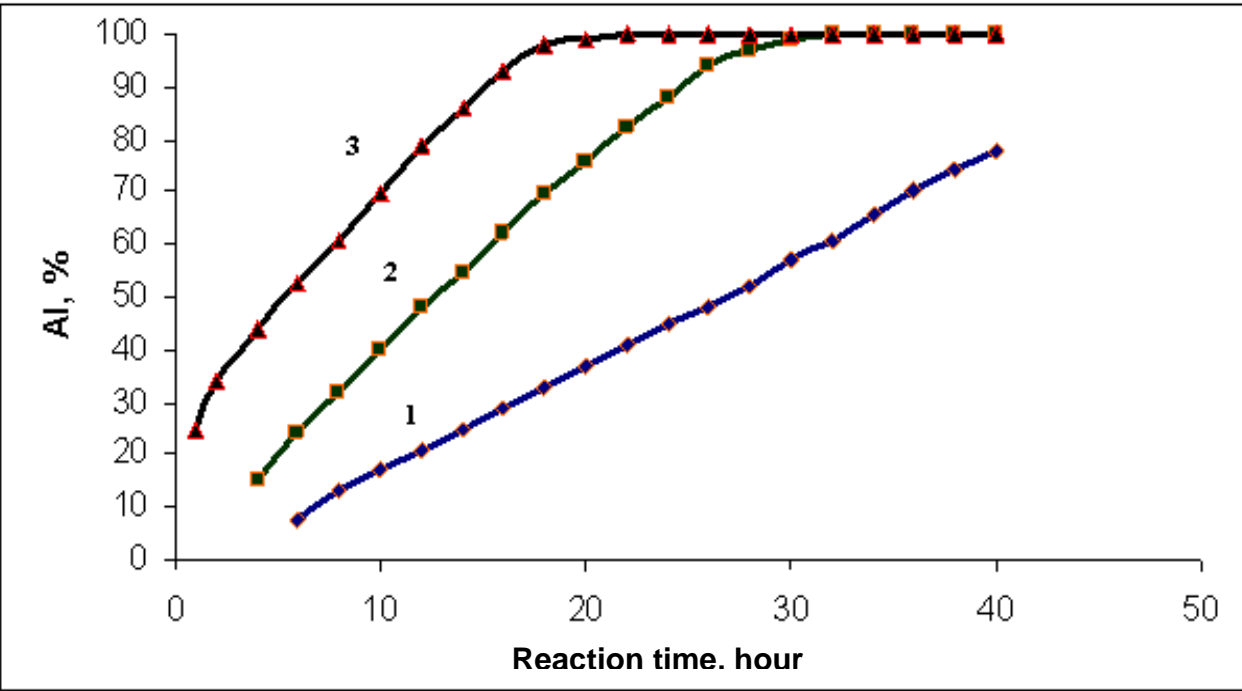

Fig 1: Graphical representation of the dependence of $\mathrm{Al}$ conversion on the reaction time at temperatures: $1-60^{\circ} \mathrm{C}$, $2-70^{\circ} \mathrm{C}, 3-80^{\circ} \mathrm{C}$.

As it can be seen from Figure1, at low temperatures interval $\left(60-70^{\circ} \mathrm{C}\right)$ for a total conversion of $\mathrm{Al}$ in the reaction requires more than 25-hours. When the temperature rises to $80^{\circ} \mathrm{C}$ it is in turn accelerating the conversion of $\mathrm{Al}$, respectively, the formation of the catalytic complex is completed at 20-22 hours. Given the boiling point of DCE, the reaction is carried out at temperatures not exceeding $80-85^{\circ} \mathrm{C}$. The temperature below $60^{\circ} \mathrm{C}$ is not sufficient to activate the surface of the aluminum metal, and therefore its interactions with DCE. 
Synthesis of bimetallic catalytic complexes was performed at molar ratios of Al to transition metal is equal 1:1 to $16: 1$.

At low ratios (Al:Me = 6:1, 4:1, 2:1, 1:1) although a complete consumption of aluminum metal process is occurred however, a part of the transition metal salt is precipitated or formed a mixture which remains in the system. At the ratios above 8:1, a complete and a simultaneous consumption of Al and the transition metal salts.

\section{Dynamic light scattering Particle Size (DLS)}

The method of DLS has been established that, the hydrodynamic sizes of all samples showed a non-symmetric distribution, and Table 2 shows the average particle size values of the bimetallic catalytic complexes. The CTC sample shows a comparison of the aggregation and impurities observed for the modified systems with metal chloride due to the addition of transition metals in the system which increases the size of particles and increases the degree of the aggregation.

Table 2. The particle size distributions and average particle size values of the bimetallic catalytic systems

\begin{tabular}{cccc}
\hline Samples name & $\begin{array}{c}\text { Diameter } \\
(\mathbf{n m}) \text { on } \mathbf{1 0 \%}\end{array}$ & $\begin{array}{c}\text { Diameter } \\
(\mathbf{n m}) \text { on } \mathbf{5 0 \%}\end{array}$ & Diameter (nm) on 90\% \\
\hline $\mathrm{CTC}$ & 11.9 & 27.4 & 44.2 \\
$\mathrm{CTC} / \mathrm{NiCl}_{2}$ & 35.7 & 87.7 & 144.4 \\
$\mathrm{CTC} / \mathrm{MnCl}_{2}$ & 37.4 & 88.2 & 142.0 \\
$\mathrm{CTC} / \mathrm{FeCl}_{3}$ & 41.7 & 95.7 & 156.4 \\
\hline
\end{tabular}

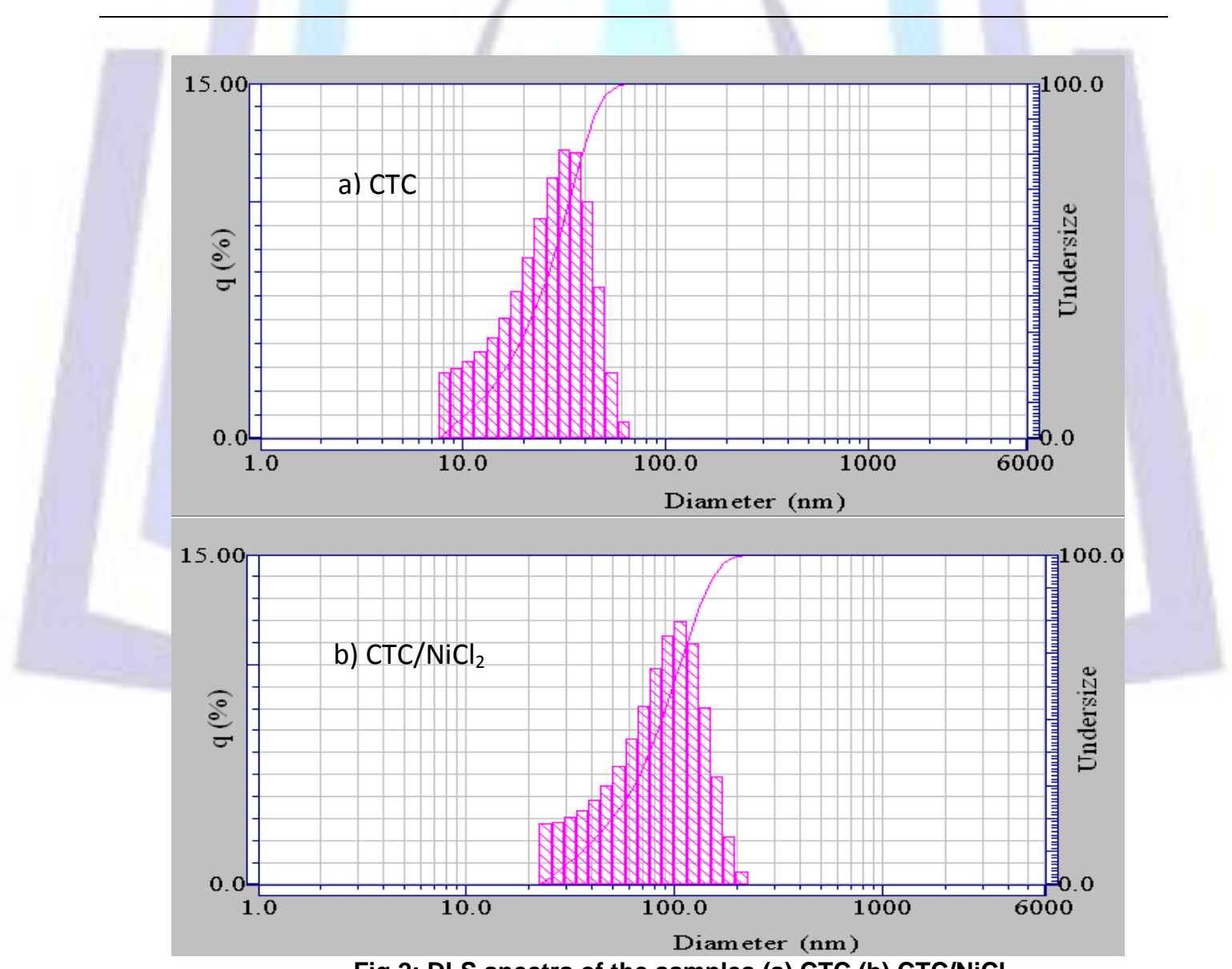

Fig 2: DLS spectra of the samples (a) $\mathrm{CTC}$ (b) $\mathrm{CTC} / \mathrm{NiCl}_{2}$

The results showed a wider size distribution and decrease in the particle size of the bimetallic catalytic complexes in the following arrange $\mathrm{CTC} / \mathrm{NiCl}_{2}<\mathrm{CTC} / \mathrm{MnCl}_{2}<\mathrm{CTC} / \mathrm{FeCl}_{3}$ depending on the composition of the synthesized bimetal catalytic system. Figure. 2 shows the different particle size distributions and different average particle size values of the samples depending on the composition as calculated by using the Stokes-Einstein equation:

$$
\mathrm{D}=\mathrm{K}_{\mathrm{B}} \mathrm{T} / 6 \pi \eta \mathrm{R}
$$


where $k_{B}$ - is the Boltzmann constant $\left(1.38 \times 10^{-23} \mathrm{~m}^{2} \mathrm{kgs}^{-2} \mathrm{~K}^{-1}\right)$, T- is temperature $(K), \eta$ - is viscosity (Pa s), R, the hydrodynamic radius.

\section{Thermal analyses of the synthesized bimetallic complexes}

The methods of TG/DTG/DTA studied the thermal properties of the synthesized bimetallic catalytic systems and the effect of $\mathrm{Fe}^{3+}, \mathrm{Mn}^{2+}$, and $\mathrm{Ni}^{2+}$ as transition metals on the formation of carbon-based materials in these catalytic systems. According to TG/DTG/DTA data it was observed that, the samples were evaluated in three stages in the temperature range of $20-800^{\circ} \mathrm{C}$ in flowing of air.

The first stage (up to $180-220^{\circ} \mathrm{C}$ ) is observed for the thermal decomposition of the crystallized water molecules, The second stage (up to $340-370^{\circ} \mathrm{C}$ ) is due to the thermal decomposition of dry solid residue CTC and its modified forms may be due to the collapse of aluminum compounds and these $3 \mathrm{~d}$ metal complexes of organic and inorganic nature with simultaneous processes of sublimation of some compounds and the evaporation of solvent residue, accompanied by an endothermic effect. The third stage of weight loss at temperatures from $350-800^{\circ} \mathrm{C}$ is characterized by the oxidative destruction of relatively stable catalyst components - metal chlorides and carbon particles. This stage is accompanied by oxidation of carbon nanoparticles with an exothermic effect $[17,18]$. At $800^{\circ} \mathrm{C}$ the modified chloride samples CTC and carbon particles are completely oxidized. From Figure. 3 it can seen that the decreasing of the maximum temperature $\left(\mathrm{T}_{\mathrm{Max}}\right)$ in the bimetallic systems associated with the oxidation of carbon particles of the catalysts due to the increase of dispersion and structural defects of carbon particles resulting from the mutual influence of transition metal ions and carbon. The dispersion growth of carbon promotes the surface area of catalytic systems as well as its function to support the bimetallic centers.
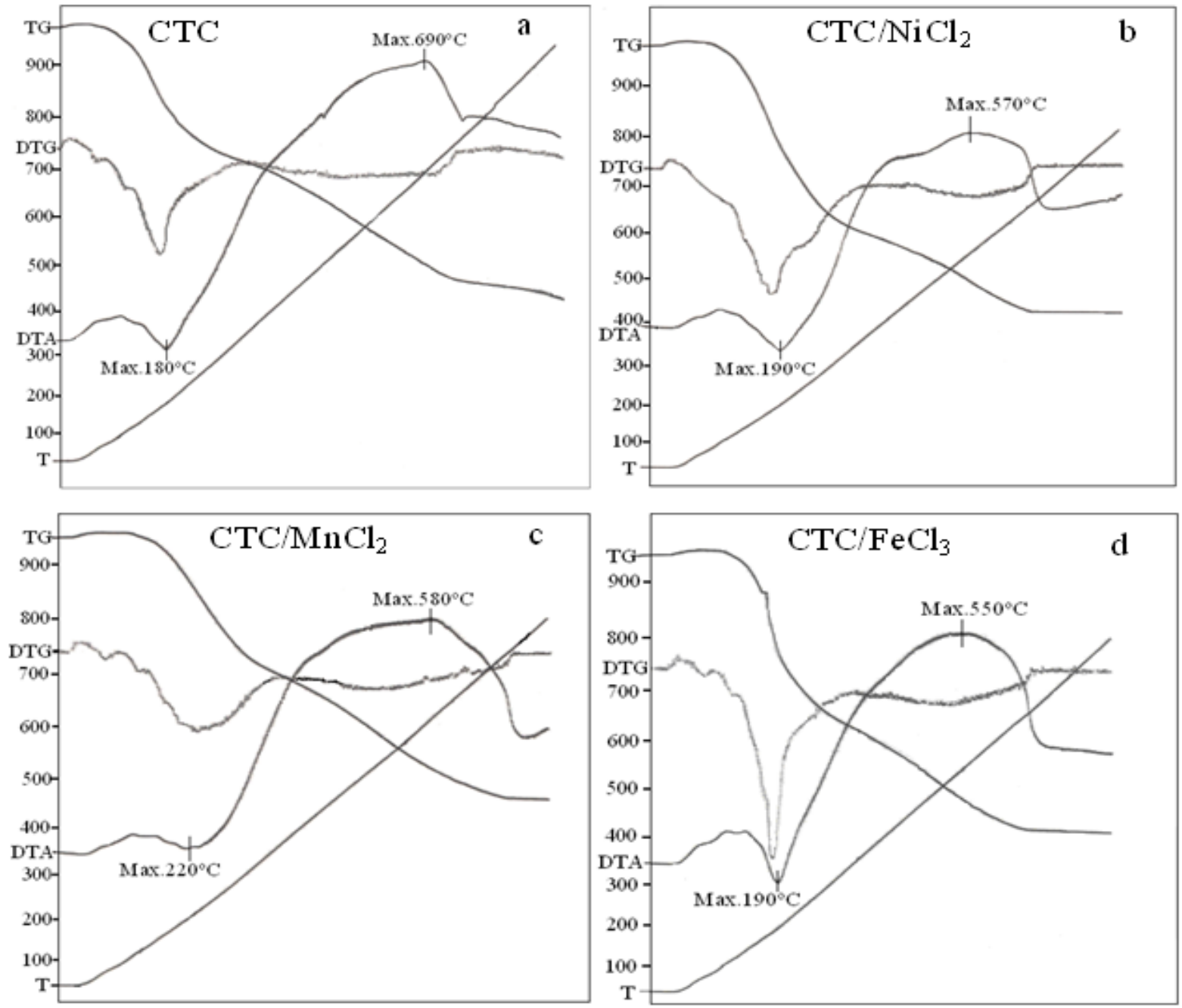

Fig 3: TG/DTG/DTA curves of the samples (a) $\mathrm{CTC}$ (b) $\mathrm{CTC} / \mathrm{NiCl}_{2}$ (c) $\mathrm{CTC} / \mathrm{MnCl}_{2}$ (d) $\mathrm{CTC} / \mathrm{FeCl}_{3}$. 


\section{XRD analyses}

XRD patterns for the samples CTC, $\mathrm{CTC} / \mathrm{FeCl}_{3}$ dried at $100^{\circ} \mathrm{C}$ are shown in Figure. 4, The patterns showed that the samples have an amorphous structure at this thermal treatment but after calcinations at $800^{\circ} \mathrm{C}$ in air crystalline phases were obtained (Fig.5), the cubic phase of $\mathrm{y}-\mathrm{Al}_{2} \mathrm{O}_{3}$ was obtained for $\mathrm{CTC}$ and for $\mathrm{CTC} / \mathrm{FeCl}_{3}$ (PDF. 00-025-0063) at 2 $\theta=$ $20^{\circ}, 34^{\circ}, 39^{\circ}, 40^{\circ}, 47^{\circ}$ and $64^{\circ}$ ), and also the phase of synthetic hematite $\mathrm{Fe}_{2} \mathrm{O}_{3}$ (PDF. 01-077-9927) at $2 \theta^{\circ}=33^{\circ}, 36^{\circ}, 49^{\circ}$, $54^{\circ}$ and $65^{\circ}$ was formed for the sample of $\mathrm{CTC} / \mathrm{FeCl}_{3}$. The same behaviors were obtained for the samples of $\mathrm{CTC} / \mathrm{NiCl}_{2}$, $\mathrm{CTC} / \mathrm{MnCl}_{2}$ (not shown) treated at $100^{\circ} \mathrm{C}$ and those which calcined at $800^{\circ} \mathrm{C}$.

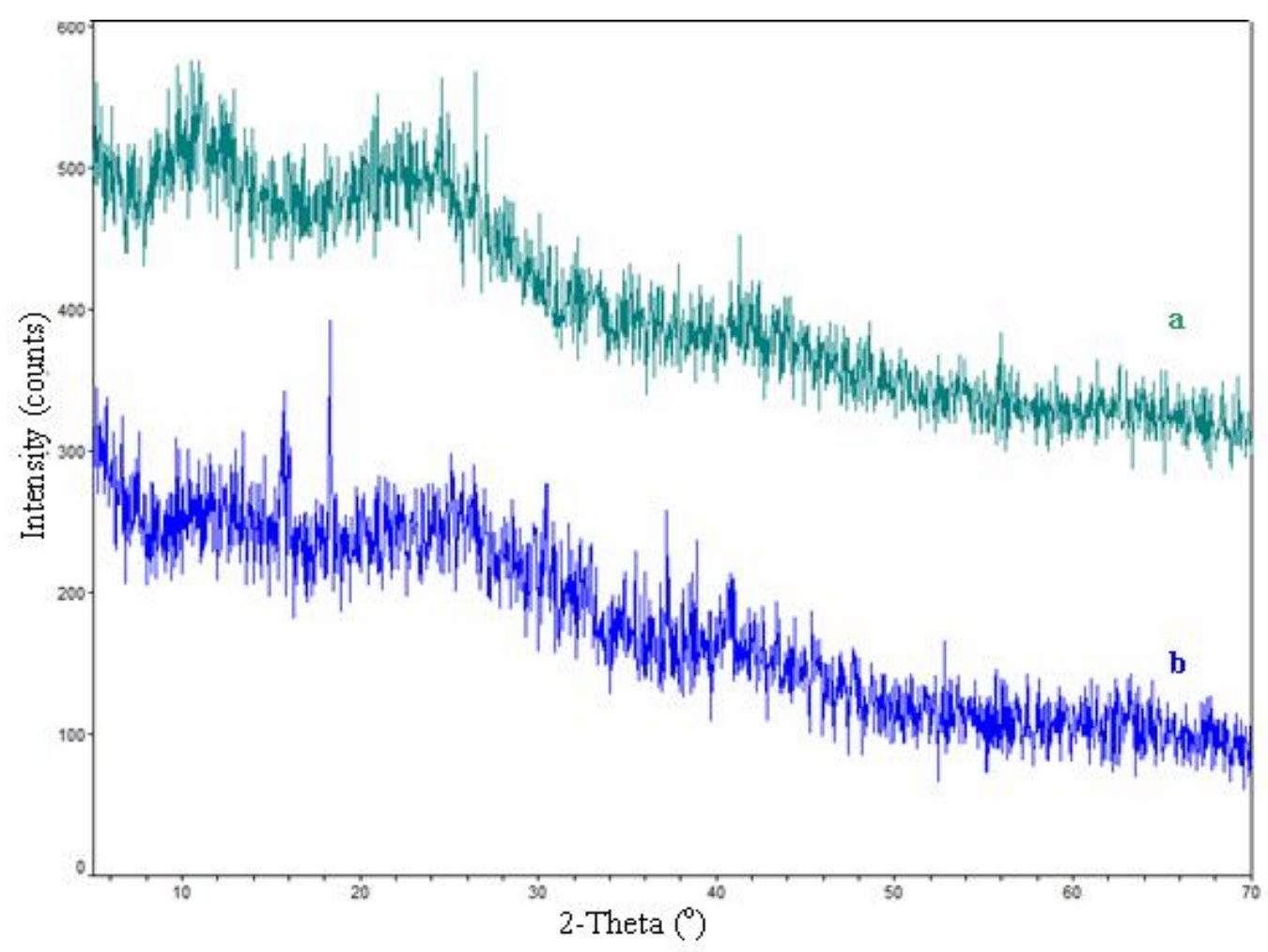

Fig 4: XRD patterns of precursor samples at $100^{\circ} \mathrm{C}$ (a) CTC (b) CTC/FeCl. 

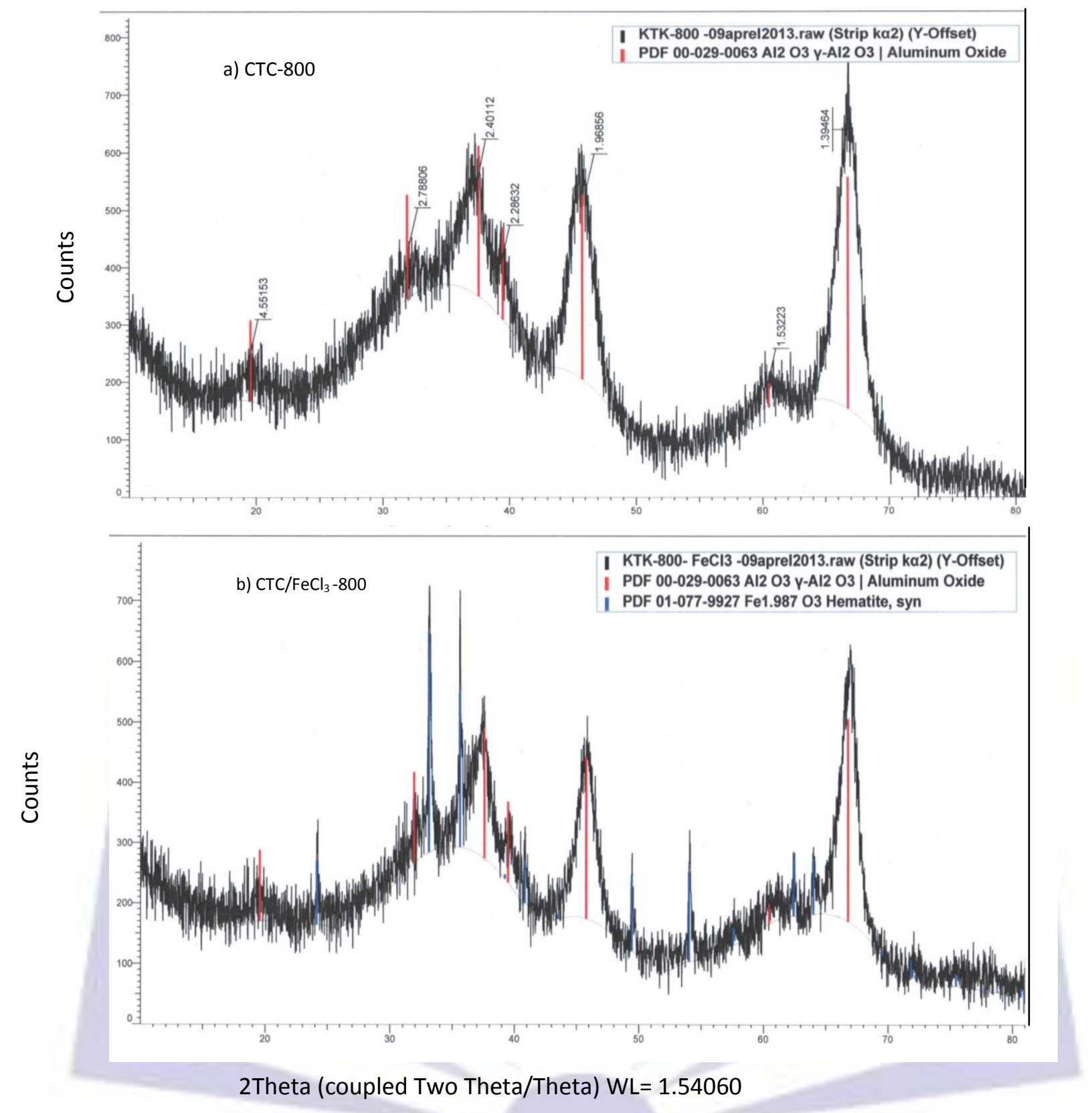

Fig 5: XRD patterns of the samples (a) $\mathrm{CTC}$ (b) $\mathrm{CTC} / \mathrm{FeCl}_{3}$ calcined at $800{ }^{\circ} \mathrm{C}$

\section{FTIR spectra}

IR spectroscopy has been used to investigate the chemical composition of the catalytic systems consisting of clusters with a certain size in the liquid phase and to explain the method of complex formation.

IR spectra of the catalytic systems showed the $2800-3000 \mathrm{~cm}^{-1}$ absorption bands belonging to the $\mathrm{v}$ - $\mathrm{CH}$ stretching vibrations mode of the corresponding to $\mathrm{CH}_{3}$ groups. In the areas of $1420-1490 \mathrm{~cm}^{-1}$ and $1313.79-1369.74 \mathrm{~cm}^{-1}$ absorption bands belonging to the bending vibrations mode of $\delta-\mathrm{CH}$ bonds corresponding to $\mathrm{CH}_{2}$ groups. As seen in the spectra of catalytic systems (Fig.6) the presence of stretching vibration mode of $\mathrm{v}\left(\mathrm{OH}\right.$ ) group in the $3300-3500 \mathrm{~cm}^{-1}$ indicates the formation of bonds $\mathrm{Me}-\mathrm{OH}$, resulting from the crystallized water molecules and moisture formed into the catalytic systems in air, this was also confirmed by thermogravimetric analysis. The detected absorption bands for the sample of CTC in the range of $600-800 \mathrm{~cm}^{-1}$ are related to the $\mathrm{C}-\mathrm{Cl}$ - bonds. The IR spectra of the catalytic samples of $\mathrm{CTC} / \mathrm{NiCl} 2$ and $\mathrm{CTC} / \mathrm{FeCl}_{3}$ in this region showed three intense absorption bands. In the spectrum of CTC sample in the region marked by three bands of low intensity in the spectrum is of the same for the sample of $\mathrm{CTC} / \mathrm{MnCl}_{2}$ at $689.92 \mathrm{~cm}^{-1}$ as an intense band. The absorption bands in the regions of $820-970 \mathrm{~cm}^{-1}$ and $1230-1280 \mathrm{~cm}^{-1}$, related to the $\mathrm{C}-\mathrm{H}$ bonds are the same for different compounds [12, 13]. 
From previous work $[15,16]$ it is revealed that, the absorption bands at $490.06 \mathrm{~cm}^{-1}$ and $524.98 \mathrm{~cm}^{-1}$ are due to the stretching vibrations mode of the tetrahedral $\mathrm{AlCl}_{4}^{-}$ions and at $584.72 \mathrm{~cm}^{-1}$ and $670-680 \mathrm{~cm}^{-1}$ band of $\mathrm{Al}_{2} \mathrm{Cl}_{7}^{-}$ions due to $\mathrm{Al}-\mathrm{Cl}$ connection. The absorption bands marked at $405.36 \mathrm{~cm}^{-1}$ and $475.12 \mathrm{~cm}^{-1}$ correspond to Al-C bonds. Lack of the absorption bands in the region $600-620 \mathrm{~cm}^{-1}$ indicates that $\mathrm{AICl}_{3}$ in a molecular form is not present in the catalytic systems.

Based on the data of IR-spectroscopy, it can be concluded that the presence of $\mathrm{C}-\mathrm{Cl}, \mathrm{Al}-\mathrm{Cl}, \mathrm{Al}-\mathrm{C}$ in the spectra, as well as methane and methylene groups indicates that during the reaction of $\mathrm{Al}$ with the DCE complexes ions are formed and belonging to the components reaction of $\mathrm{Al}_{2} \mathrm{Cl}_{6}, \mathrm{AIRCl}_{2}$ and $\mathrm{AIR} \mathrm{Rl}_{2} \mathrm{Cl}\left(\mathrm{R}-\mathrm{C}_{2} \mathrm{H}_{5}, \mathrm{C}_{3} \mathrm{H}_{7}\right)$.
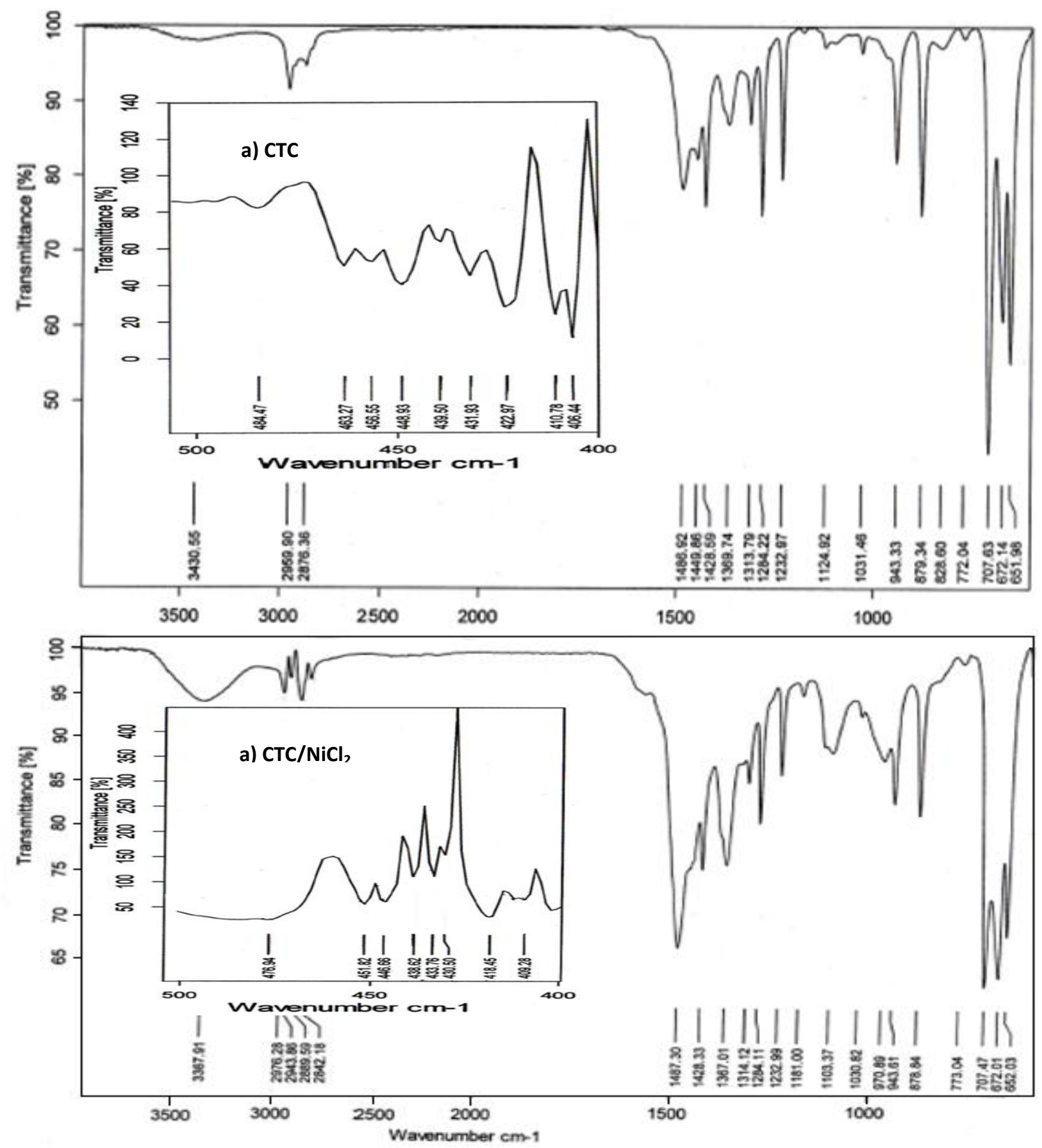

Fig 6: FTIR spectra of samples (a) $\mathrm{CTC}$ and (b) $\mathrm{CTC} / \mathrm{NiCl}_{2}$ 
The presence of $\mathrm{C}-\mathrm{Cl}$ bond proved the formation catalytic complexes from the reaction of $\mathrm{AlCl}_{3}$ with dicholoroethane (DEC), along with the above complex compounds forms $\mathrm{AlCl}_{4}{ }^{-} \mathrm{C}_{2} \mathrm{H}_{4} \mathrm{Cl}^{+}$ions. The assumed CTC and its bimetallic complexes can be represented as follows:<smiles>Cl[Al]1(Cl)C[Si](Cl)(Cl)[Si]1(Cl)Cl</smiles><smiles>C=C1CCC1(Cl)CC(Cl)(Cl)Cl</smiles><smiles>Cl[Al]1[CH]C(Cl)(Cl)C1</smiles><smiles></smiles>

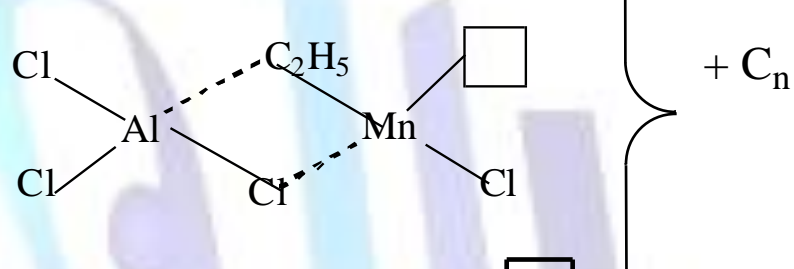<smiles>C=C1CCC1(Cl)Cl</smiles>

\section{XRFM analysis}

As discussed above, the catalyst CTC is the solid product of the reaction between aluminum metal and dichloroethane. The solid products which dried at $100^{\circ} \mathrm{C}$ represent a composite of inorganic salts and carbon particles. These solid residues of samples were characterized by XRF analysis as shown in Table 3. Data Listed in Table 3 showed that, the elemental distributions of these metals in the carbon matrix are significantly different for each sample (Fig.7).

Table 3. Percentage of elements in the samples and their distribution over the depth at $100^{\circ} \mathrm{C}$

\begin{tabular}{|c|c|c|c|c|c|c|c|c|c|}
\hline \multirow{2}{*}{ Samples name } & \multicolumn{6}{|c|}{ Elements, wt\% } & \multicolumn{3}{|c|}{$\begin{array}{l}\text { Element distribution over } \\
\text { depth, } \mu \mathrm{m}\end{array}$} \\
\hline & $\mathrm{Al}$ & $\mathrm{Cl}$ & $\mathrm{C}$ & $\mathrm{Mn}$ & $\mathrm{Fe}$ & $\mathrm{Ni}$ & $\mathrm{Mn}$ & $\mathrm{Fe}$ & $\mathrm{Ni}$ \\
\hline CTC & 8.88 & 35.04 & 56.08 & - & - & - & - & - & - \\
\hline $\mathrm{CTC} / \mathrm{MnCl}_{2}$ & 9.37 & 40.51 & 47.36 & 2.76 & - & - & 0.123 & - & - \\
\hline $\mathrm{CTC} / \mathrm{FeCl}_{3}$ & 6.43 & 47.29 & 43.11 & - & 3.17 & - & - & 0.124 & - \\
\hline $\mathrm{CTC} / \mathrm{NiCl}_{2}$ & 11.81 & 49.90 & 35.53 & - & - & 2.76 & - & - & 0.885 \\
\hline
\end{tabular}

For the samples after thermal treatment at $800^{\circ} \mathrm{C}$ it was observed that the metal salts converted into oxides as example the elemental distribution of CTC sample is made up $99.02 \%$ of aluminum oxide and $0.98 \%$ of carbon. These elemental distributions of the bimetal catalytic systems after the thermal treatments of samples at $800^{\circ} \mathrm{C}$ provided the 
formation of the metal oxides at higher temperature and this fact is agreed with the XRD diffraction analyses accompanied with the formation of $\mathrm{y}-\mathrm{Al}_{2} \mathrm{O}_{3}$, hematite $\mathrm{Fe}_{2} \mathrm{O}_{3}, \mathrm{MnO}_{2}$ and nickel dioxide $\mathrm{NiO}_{2}$ phases.
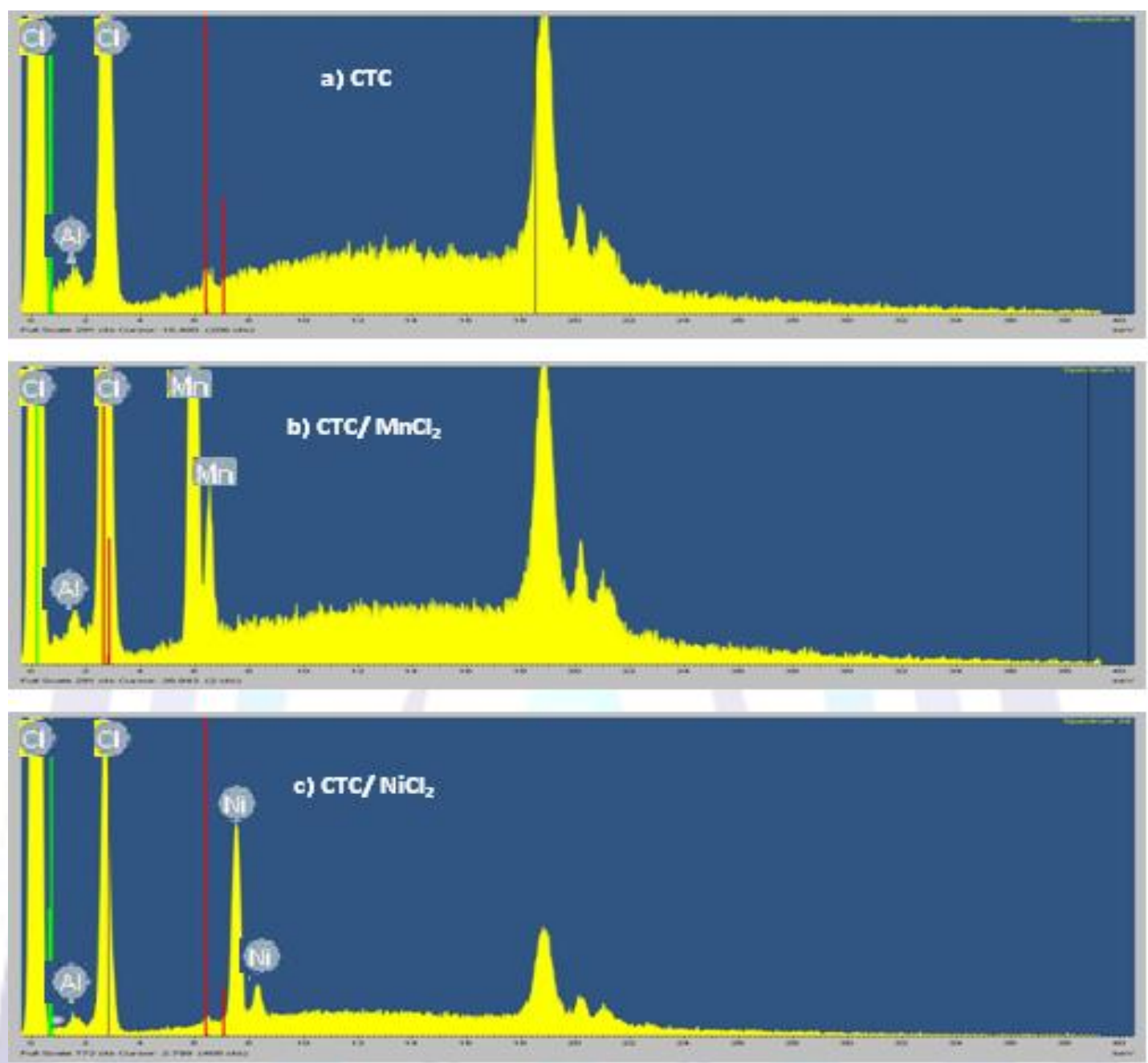

Fig 7: XRF analysis of the samples (a) CTC (b) $\mathrm{CTC} / \mathrm{MnCl}_{2}$ (c) $\mathrm{CTC} / \mathrm{NiCl}_{2}$

\section{CONCLUSIONS}

This work discussed the synthesis and study of the initial catalytic complex CTC and its modified bimetallic catalytic complexes of $\mathrm{CTC} / \mathrm{FeCl}_{3}, \mathrm{CTC} / \mathrm{MnCl}_{2}$ and $\mathrm{CTC} / \mathrm{NiCl}_{2}$ by the reaction of fine-dispersed $\mathrm{Al}$ metal with dichloroethane in paraffin medium in the presence of $\mathrm{Fe}$ (III), $\mathrm{Mn}$ (II) and $\mathrm{Ni}(\mathrm{II})$ chlorides as modifiers. This chemical-based synthesis route is briefly described, and the best conditions to synthesis these catalytic systems are concluded as follow: normal hydrocarbon is used as solvent as aromatic hydrocarbons with dichloroethane (DCE) accumulated in the system and makes the synthesis step is so difficult, the reaction is carried out at temperatures not exceeding $80-85^{\circ} \mathrm{C}$ as below $60{ }^{\circ} \mathrm{C}$ it can not activate the surface of aluminum metal, the formation of the catalytic complex is completed at 20-22 hours and the best molar ratios of $\mathrm{Al}$ to transition metal is more than 8:1 to a complete consumption of $\mathrm{Al}$ metal and transition metal salts. the structures of the obtained catalytic systems have been confirmed by using different characterization techniques such as dynamic light scattering spectroscopy (DLS), thermal analyses (TG/DTG/DTA), X-ray diffraction (XRD), FTIR spectroscopy, and X-ray fluorescence microscopy (XRFM) which revealed the presence of aluminum, iron, $\mathrm{Mn}$ and $\mathrm{Ni}$ chlorides, and their nanoscale structures including the elemental distribution and mass thickness of the these elements over the layers. The XRD results also presented crystalline metal oxide phases of these catalysts in their inner structure after thermal treatment at $800^{\circ} \mathrm{C}$. It can be assumed that the formation of these metal oxides is confirmed the presence of the metal chlorides as modifiers at the lower temperature $100 \stackrel{\circ}{\mathrm{C}}$.

\section{REFERENCES}

[1] Bulkatov, A.N. Analysis of the technical level of pyrolysis processes for the production of ethylene and propylene, Chemical and Petroleum Engineering, 2008, v.44, No 11-12, p.642-647.

[2] Koyo Norinaga, Olaf Deutschmann, Naomichi Saegusa, Jun-ichiro Hayashi. Analysis of pyrolysis products from light hydrocarbons and kinetic modeling for growth of polycyclic aromatic hydrocarbons with detailed chemistry, J.Anal.Appl. Pyrolysis, v. 86, 2009, p. 148-160. 
[3] Netzer, D., Ghalayini, O. J., Improve benzene production from refinery sources, Hydrocarbon processing, 2002, april, p.71-78

[4] Dumskiy Yu.V., No, B.I., Butov, G.M., Chemistry and technology of petroleum polymere resins, - Moscow: Chemistry, 1999, p.312.

[5] Dariush Salari., Azadeh Jodaei., Petroleum resin preparation by cationic polymerization of pyrolysis gasoline, Iranian Polymer Journal, 2006, v.15, No 1, p.55-64.

[6] Bondaletova, L.I., Bondaletov, V.G., Verevkina, O.V., Manankova, A.A., Determining structure of petrolium polymer resins obtained on the basis of high boiling fractions of pyrolysis liquid products, Bulletin of the Tomsk Polytechnic University, 2007, v.311. № 3, p.101-105.

[7] Silvio Vargiu., Process for the preparation of petroleum resins. Patent USA. No: 3905948, Declared: December 26, 1973, Issued: September 1, 1975

[8] Kaputskii, F.N., Mardykin, V.P., Gaponik, L.V., Lesnyak, V.P., Kostyuk, S.V., Mil'chanina, T.L. Synthesis of petroleum polymeric resin by cationic polymerization of the $\mathrm{C}_{9}$ fraction, Russian Journal of Applied Chemistry, 2002, v.75, No.6, p.1006-1008(3).

[9] Ibrahimov, H.C., Joerg F., Friedrich, İsmailov, E.H. et al. Thermal and magnetic peculiarities of metal-containing carbon nano-phase formed in the reaction of fine-dispersed aluminum with dichlorethane in paraffin medium, Journal of Chemistry and Chemical Engineering (A), 2012, A 2 (2), p.196-202.

[10] Ibragimov, Kh.D., Ismailov, E.G., Martynova, G.S., Bektashi, N.R., Ibragimova, Z.M., and Rustamov, M.I., Synthesis of a Component of the Jet Engine Fuel and an Accelerator of Oil Tar Oxidation by Catalytic Processing of Heavy Pyrolysis Tar, Russian Journal of Applied Chemistry 2010, v.83(7), p.1259-1263.

[11] Ibragimov, Kh.D., Gasimova, K.M., Ismailov, E.G., etc., Nanostructured Mn, Fe, Ni-containing catalysts for the oligomerization of $\mathrm{C}_{6}-\mathrm{C}_{8}$ pirocondensate fraction, Symposium Modern Problems of nanocatalysis" Book of Abstracts, oje city, 2012, p.145-146.

[12] Luinge, H.J. Automated interpretation of vibration spectra, Vib. Spectroscopy, 1990, v.1, p.13-18.

[13] Smith, A., Applied Infrared Spectroscopy, Moscow, 1982, p.328.

[14] Klaeboe, P., Rytter, E., Sjøgren, C.E., Infrared high temperature spectra of aluminium chloride and related species, Journal of molecular structure, 1984, v.113. p.213 - 226.

[15] Hvistendahl, J., Klaeboe, P., Rytter, E. et al., Infrared emission spectra of alkali chloroaluminates and related melts, Inorganic chemistry, 1984, v.23, № 6, p.706-715.

[16] Arbuzov, A.B., Drozdov, V.A., Trenikhin, M.V., Kudrya, E.N., Talsi, V.P., Likholobov, V.A. Study of the reaction of activated aluminium with tert- $\mathrm{C}_{4} \mathrm{H}_{9} \mathrm{Cl}$, Abstracts of VIII International Conference "Mechanisms of Catalytic Reactions" dedicated to the 70th anniversary of professor Kirill I. Zamaraev, Novosibirsk, Russia, June 29 - July 2 2009, v.I., p.122.

[17] Obraztsov, A.N., Kopylov, P.G., Chuvilin, A.L., Savenko, N.V., Diamond and Related Materials, 2009, v.18, p.12891295

[18] Karaeva, A.R., Dolgova, E.A., Kharitonov, D.N. et al., Ruc.Chem.journal, 2006, v. L. №1, p.64-67

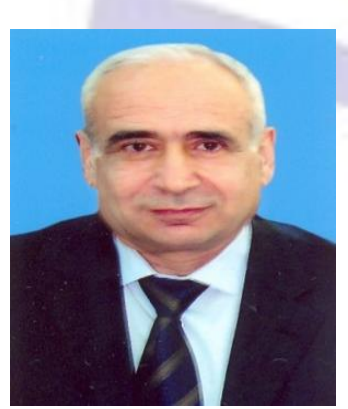

Hikmet Jamal İbragimova. Doctor of Technical Sciences, Azerbaijan National Academy of Sciences, Institute of Petrochemical Processes. Vice director of Institute of Petrochemical Processes. 62 years old. He has more than 157 scientific and 19 patent. His Main area of activity: Development of new systems of catalytic cracking and pyrolysis, modernization of the existing ones, development of the technology for deepening of oil-refining and products of the catalytic cracking and pyrolysis satisfying by quality the world standards.

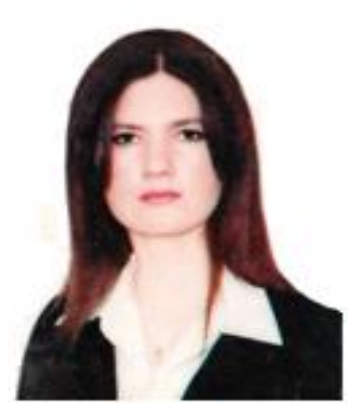

Kenul Murvat Gasimova. 29 years old. Working as researcher in Azerbaijan national academy of science, institute of petrochemical processes, PhD student in institute of petrochemical processes, Department of catalytic cracking and pyrolysis. She has more than 21 paper and theses in international journals and conferences. Her Main scientific achievements have been developed the theoretical foundations, synthsis and analysis of catalytic complexes and treating of pyrolysis liquid products. 


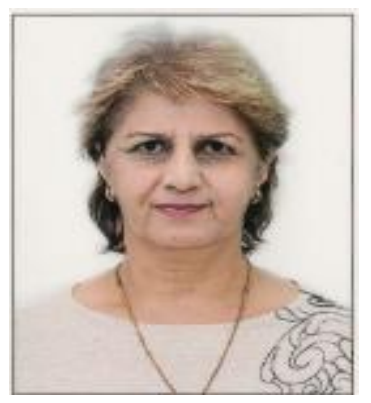

Zenfira Maherram Ibragimova. 60 years old.

Working as Fellow senior researcher in Azerbaijan national academy of science, institute of petrochemical processes, has more than 57 scientific works. She has innovated a technologic complex scheme with few stages and allows to produce ethyl benzene, naphthaline, oligomers of different purposes, solvents etc.

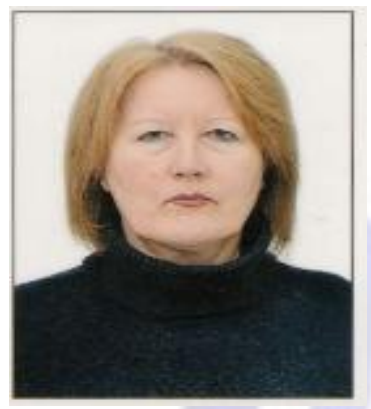

Irina Valentinovna Kolchikova. Nationality is Russian. 56 years old. Working as Senior Researcher in Azerbaijan national academy of science, institute of petrochemical processes, has 30 scientific works. She has been worked out the scheme of the pyrolysis liquid products refining using the catalytic complex of which has been commercialized.

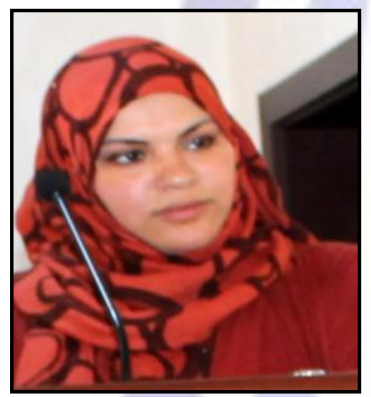

Mai Mostafa Khalaf. Nationality is Egyptian. 29 years old. She received the master degree in physical chemistry from the University of Sohag, Sohag, Egypt, in 2010. working as assistant lecturer in chemistry department, faculty of science, Sohag University. PhD student in Azerbaijan national academy of science, institute of petrochemical processes, She is an author on more than 18 international scientific works. Her current research focused on scientific foundation for the effective heterogeneous catalysts prepation for the oil chemistry and for various nano-technological applications.

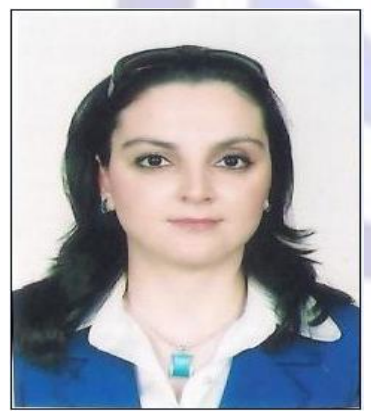

Aynura Enver Alieva. 30 years old. Working as assistant in Azerbaijan State Oil Academy, PhD student in Azerbaijan national academy of science, institute of petrochemical processes, has 4 papers. 